\title{
Evaluating the Role of Life Events and Sustaining Conditions in Weight Loss Maintenance
}

\author{
Eleni Epiphaniou and Jane Ogden \\ Department of Psychology, University of Surrey, Guildford, Surrey, GU2 7HX, UK \\ Correspondence should be addressed to Eleni Epiphaniou, eleni.epiphaniou@kcl.ac.uk \\ Received 17 September 2009; Accepted 19 April 2010 \\ Academic Editor: Linda McCargar
}

Copyright ( $) 2010$ E. Epiphaniou and J. Ogden. This is an open access article distributed under the Creative Commons Attribution License, which permits unrestricted use, distribution, and reproduction in any medium, provided the original work is properly cited.

\begin{abstract}
Background. Recent qualitative research indicates that life events can enhance behaviour change maintenance. if a number of sustaining conditions are met. This study aimed to quantitatively test this theory in the context of weight loss maintenance. Method. Based upon their weight histories participants were classified as either successful $(n=431)$ or unsuccessful $(n=592)$ dieters and all completed questionnaires relating to life events, choice, the function of eating and exercise and the model of their weight problem. Findings. Successful dieters reported a higher number of life events than unsuccessful dieters particularly for events such as "clothes did not fit me", "doctor's recommendation" and "reached my heaviest weight". Successful participants also indicated reduced choice over their previous unhealthy diet, more choice over their exercise behaviours and more benefits from the new healthy behaviours. They were also less likely to attribute their previous increased weight to any medical and psychological factors. This was accompanied by a belief about the effectiveness of behavioural solutions to their weight problem. Discussion. Life events can promote behaviour change for some individuals. This change is facilitated by a reduction in choice and disruption of function over the unhealthy behaviours, and a belief that behavioural solutions will be effective.
\end{abstract}

\section{Introduction}

Obesity has been significantly associated with various negative physical and psychological problems. Healthy and sustained behaviour change improves individuals' physical and psychological well-being and minimises social cost. Social cognition models (SCMs) indicate how behaviour change emerges from the interaction of attitudes, intentions and individuals' expectations based on the perceived positive and negative outcomes regarding the behaviour [1]. These models argue that health behaviour change is the end outcome of gradual decision making from behavioural intentions and action plans towards the performance of behaviour [2]. For example, social cognition models support the notion that people will intend to lose weight when they have more positive attitudes towards healthy behaviour, improved selfefficacy and a greater sense of control. However, despite the models' widespread applicability to explore the predictors for the initiation of healthy behaviours, researchers argue that they fail to reveal the factors which explain sustained behaviour change [3].
Contrary to the above focus on gradual cognitive shifts, there is much research which indicates that behaviour change is not always the outcome of planned decisions, but may occur suddenly after a specific event. Such events have been described using a number of terms such as epiphanies, life events, medical triggers, teachable moments, and life crises [4-8]. In the area of weight loss maintenance Gorin et al., [4] and Wing \& Phelan [9] concluded that medical triggers were associated with more weight loss and sustained weight loss in a group of successful weight loss participants. While Tinker \& Tucker [10] described how negative events enhance weight loss and weight loss maintenance. Likewise, in the field of smoking behaviour authors West \& Sohal [11] and Larabie [5] reported how exsmokers who quit smoking "cold-turkey" without any previous planning, were more likely to maintain their behaviour change than individuals who quit after previous planning. Consequently, for some individuals, life triggers can be one of the possible reasons behind behaviour change.

Some research, however, indicates that while for some individuals these salient events enhance behaviour and 
sustained behaviour change, for others this behaviour change appears only in the short term (Brink \& Ferguson, 1998) [12]. This response variability around life events therefore raises the question: "when a sudden milestone threatens an individual's equilibrium, what are those conditions which enhance sustained behaviour change and more specifically sustained weight loss maintenance?"

Ogden and Hills [13] carried out a series of qualitative interviews with individuals who had shown changes in either their smoking habits or body weight for three or more years, as a means to explore those mechanisms associated with either smoking cessation, or weight loss maintenance. The authors concluded that sustained behaviour change is often precipitated by a salient event such as a relationship breakdown, an illness, or a change in job. They then further argue that this initial behaviour change is transformed into sustained behaviour change if a number of sustaining conditions are met. In particular, according to this model the behaviour change is sustained if the choice over the old behaviour is reduced, the function of the previous behaviour is disrupted and individuals endorse a behavioural model of their weight problem focusing on behavioural causes and behavioural solutions. To date this model has not been tested using quantitative methodology.

In line with this, the present study aimed to further explore the role of specific life events in behaviour change and to operationalize these sustaining conditions using a quantitative approach. In particular, the study aimed to examine differences between successful and unsuccessful dieters in terms of sudden events, choice and function, over eating and exercise, and attributions and solutions to their increased weight problem. It is possible, however, that differences not only exist between different groups of people but also within people at different times of their lives. Therefore, a within subject analysis was also carried out to explore differences within the successful group, between a time when they had been at their heaviest and over the past month whilst they were maintaining their weight loss. It was hypothesized that successful weight loss maintenance would be associated with more life events, a perception of reduced choice over their previous eating and exercise behaviour, more perceived benefits from their new healthier behaviour, and a focus on behavioural attributions and solutions to their weight problem.

\section{Method}

2.1. Design. The study applied a within and a between subjects design. The between subjects design examines the difference between the successful and unsuccessful group while the within subjects design explores the differences within the successful group in regards to their weight loss experiences between their heaviest and current weight.

2.2. Participants. Participants were members of a UK-based slimming club and were recruited via an online advertisement which was posted on the club's website. One thousand ninety three members completed an initial screening questionnaire concerning their weight history to enable them to be grouped as successful or unsuccessful dieters. On the screening questionnaire participants were providing their consent to complete the screening questionnaire and also to participate to the follow-up study by indicating their email or home address.

Participants were members of a private slimming club in the UK. Through the club's eating plan, members are encouraged to maintain a healthy, balanced diet which includes more low-energy dense foods and less high-energy dense foods. Exercise is also introduced in their daily lives with different forms of exercise being integrated into their individual, every day life.

2.3. Measures. Two questionnaires were used in the study: the Screening questionnaire and the Follow-Up questionnaire.

2.4. Screening Questionnaire. The screening questionnaire included questions on (i) demographics, (ii) participants' weight history, and (iii) contact details.

(i) Demographics. Participants described their age, sex, ethnicity, work, relationship status, and level of education.

(ii) Weight History. Participants were also asked to report their current weight and height, their highest weight excluding pregnancy, lowest weight since being 18 years old, most weight ever lost, age when first became overweight and age when first tried to lose weight. Finally, they completed their weight history since they were 18 years old up to their current age in two years intervals. This aimed to categorize them into two groups: successful and unsuccessful participants based on their weight history.

(iii) Contact Details. Participants were asked to provide their contact details. Their details were used to send the follow-up questionnaire. Participants were informed that by providing their contact details they were giving their consent to receive the follow-up questionnaire.

2.5. Follow-Up Questionnaires. There were two main questionnaires designed separately for the successful and unsuccessful participants. Unsuccessful participants were asked to concentrate on their weight loss experiences "During the Past Month" whereas successful participants were asked to indicate their weight loss experiences in two different time periods that is, when they were "At Their Heaviest" and "During the Past Month". The aim was to explore their weight experiences during their heaviest weight and while maintaining their weight loss. Both questionnaires measured 5 variables each of the time which were based on the Ogden and Hill's model of sustained behaviour change: (i) behavioural model of obesity: perceived causes and behavioural solutions, (ii) function of diet and exercise, (iii) choice over diet and exercise, (vi) life events. 
(i) Behavioural Model of Obesity. This question asked participants to indicate their beliefs about the causes of obesity and the behavioural solutions applied based on those beliefs.

Perceived Causes. Participants, on a scale from 1 (strongly disagree) to 5 (strongly agree), were asked to indicate the extent to which they agreed that their weight was due to low exercise (3 items e.g. lack of exercise, not being physically active) (Cronbach's alpha $=.89)$, diet reasons $(3$ items e.g., eating when not hungry, eating sweet foods) (Cronbach's alpha $=.77)$, medical reasons (3 items e.g., genetics, hormone imbalance) (Cronbach's alpha $=.76)$ and psychological reasons (3 items e.g. depression, laziness) (Cronbach's alpha $=.60)$.

Behavioural solutions. Participants were asked to indicate, on a scale from 1 (not at all) to 5 (to a great extent), whether they engaged in some behaviours. These behaviours referred to exercise ( 3 items e.g. walk, spend hours watching TV) (Cronbach's alpha $=.60)$ and diet $(7$ items e.g., boil or bake food, eat fruit and vegetables) (Cronbach's alpha $=.60$ ).

(ii) Function of Behaviours. Participants were asked to indicate the perceived benefits which they experienced from their eating and exercise behaviour. Eating: (4 items e.g., Eat for comfort, eat to reduce sadness) (Cronbach's alpha $=.70$ ). Exercise: ( 3 items e.g., exercise to look good, exercise to reduce boredom) (Cronbach's alpha $=.75)$.

(iii) Choice Over Behaviour. Participants indicated the degree of choice they had over their eating and exercise behaviour which was formulated from previous research. On a scale from 1 (very easy) (i.e., more choice) to 5 (very difficult) (i.e., less choice) participants reported the choice over Exercise: (3 items e.g., walk, watch TV) (Cronbach's alpha $=.60)$ and Diet: (7 items e.g., cook food, eat between meals) (Cronbach's alpha $=.67)$.

(iv) Life Events. Participants were asked to indicate YES if they had experienced or NO if they had not experienced the events indicated in the questionnaire. Life events included heart attack, sleep apnea, relationship break-up, new relationship, difficulty to walk a mile, breathing problems, deciding to have children, reaching their heaviest weight, clothes not fiting, doctor recommendations, starting a new job, family member with a serious illness, and being teased by spouse or co-workers. These were derived from qualitative research which has explored the kinds of triggers to sustained changes in behaviour (Ogden and Hills) [13].

2.6. Procedure. The study was approved by the University of Surrey Ethics Committee and the director of the slimming club. This was a convenience sample.

Initially, all participants were asked to complete the screening questionnaire which was online on the slimming club's website. Members' weight history would enable the researchers to decide whether they were successful or unsuccessful. A $10 \%$ weight loss was set as the minimum weight that participants needed to lose to be identified as successful as research indicates that this can be beneficial for their physical and psychological health [14]. Thus, unsuccessful participants were those members who lost less than $10 \%$ of their weight. In addition, to be identified as successful participants also had to maintain their weight loss for a minimum of 1 year. Based on these criteria 431 (42\%) participants were identified as successful and $592(58 \%)$ as unsuccessful.

2.7. Response Rate. From the general sample (1093) 170 participants were excluded from the analysis either because they did not provide their consent or because they did not complete their full weight history. Therefore, the remaining 923 (392 successful, 531 unsuccessful) participants received the follow-up questionnaire. Among them 237 (60\%) in the successful group and $328(61 \%)$ in the unsuccessful group completed and returned the follow-up questionnaire through email.

2.8. Analysis. Descriptive statistics, MANOVA and Chisquare tests were applied to explore the research questions using SPPS 15.

\section{Results}

Initially participants' demographic and weight characteristics were analyzed. Then the differences in weight and demographic details were explored between participants who were included in the analyses because they completed their demographic and weight details in full and those who were excluded because their weight history was incomplete. This was followed by the analyses of differences between successful and unsuccessful dieters in terms of the life events and sustaining conditions. Finally, results include a within subjects analysis which aimed to explore successful dieters' experiences between their heaviest weight and weight during the past month.

\subsection{Demographics and Weight Characteristics}

(i) Successful \& unsuccessful participants' demographic and weight history data. The majority of successful participants were white women with a mean age of 37 years. Most successful participants worked full time and were married with the majority being educated up to the GCSE/O' Level. Concerning their weight history the majority of the successful participants were overweight with few of them being in the obesity class I category. Their highest weight excluding pregnancy was $215.6 \mathrm{lbs}$. Successful participants were in their late teens and early twenties when first became overweight and first attempted to lose weight, respectively. Finally, successful members lost on average $18 \%$ of their initial weight and kept this weight off for a minimum of 4.1 years.

Similarly to the successful group, the majority of the unsuccessful participants were white women with a mean age of 37.8. Similarly with the successful participants, the 
Table 1: Demographic and weight history data for each group.

\begin{tabular}{|c|c|c|}
\hline Variable & Successful $(N=431)$ & Unsuccessful $(N=591)$ \\
\hline Age & $\mathrm{M}=39 \mathrm{SD}=10.6$ & $\mathrm{M}=38 \mathrm{SD}=10.3$ \\
\hline \multicolumn{3}{|l|}{ Sex } \\
\hline Female & $423(98.8 \%)$ & $578(97.8 \%)$ \\
\hline Male & $4(.9 \%)$ & $12(2 \%)$ \\
\hline \multicolumn{3}{|l|}{ Ethnicity } \\
\hline Caucasian & $416(97.4 \%)$ & $569(96.8 \%)$ \\
\hline \multicolumn{3}{|l|}{ Work } \\
\hline Full time & $246(57 \%)$ & $345(58 \%)$ \\
\hline Part time & $105(24.4 \%)$ & $122(20.6 \%)$ \\
\hline \multicolumn{3}{|l|}{ Relationship Status } \\
\hline Living with a partner & $96(22.3 \%)$ & $120(20 \%)$ \\
\hline Married & $222(51.5 \%)$ & $343(58 \%)$ \\
\hline Divorced & $27(6.2 \%)$ & $30(5 \%)$ \\
\hline \multicolumn{3}{|l|}{ Education } \\
\hline Less than or equal to GSCE/O Level & $185(43 \%)$ & $237(40 \%)$ \\
\hline A level & $107(25 \%)$ & $155(26 \%)$ \\
\hline Degree & $138(32 \%)$ & $197(33 \%)$ \\
\hline BMI & $\mathrm{M}=29 \mathrm{~kg} / \mathrm{m}^{2} \mathrm{SD}=5.4$ & $\mathrm{M}=33 \mathrm{~kg} / \mathrm{m}^{2} \mathrm{SD}=7$ \\
\hline Normal weight $\left(18.5-24.9 \mathrm{~kg} / \mathrm{m}^{2}\right)$ & $21 \%$ & $7 \%$ \\
\hline Overweight $\left(25-29.9 \mathrm{~kg} / \mathrm{m}^{2}\right)$ & $41 \%$ & $31 \%$ \\
\hline Obese class I $\left(30-34.9 \mathrm{~kg} / \mathrm{m}^{2}\right)$ & $23 \%$ & $27 \%$ \\
\hline Obese class II (35-39.9 kg/m²) & $10 \%$ & $16.5 \%$ \\
\hline Obese class III $\left(\geq 40 \mathrm{~kg} / \mathrm{m}^{2}\right)$ & $4.6 \%$ & $16 \%$ \\
\hline Highest weight excluding pregnancy & $\mathrm{M}=215.6 \mathrm{lbs} \mathrm{SD}=43.8$ & $\mathrm{M}=207.6 \mathrm{lbs} \mathrm{SD}=46.3$ \\
\hline Age when first became overweight & $\mathrm{M}=18 \mathrm{SD}=8.7$ & $\mathrm{M}=20 \mathrm{SD}=9.9$ \\
\hline Age when first tried to lose weight & $\mathrm{M}=22 \mathrm{SD}=8.5$ & $\mathrm{M}=23 \mathrm{SD}=9.3$ \\
\hline Percentage of weight loss & $18 \%$ & $3.2 \%$ \\
\hline Months of maintenance & $\mathrm{M}=49.6 \mathrm{~m}(4.1 \mathrm{y})$ & $\mathrm{M}=21.4 \mathrm{~m}(1.8 \mathrm{y})$ \\
\hline
\end{tabular}

majority worked full time, were married, and had been educated up to the GCSE/O'Level. Their weight history showed that unsuccessful participants were in the obesity class I and II categories. In addition, there seems to be more unsuccessful than successful participants in the obesity class II category. Their highest weight, excluding pregnancy was, 207.6 lbs. Unsuccessful participants were in their early twenties when first became overweight and attempted to lose weight and on average they lost $3.2 \%$ of their weight which they kept off for at least 1.8 years (Table 1 ).

\subsection{Participants Included and Participants Excluded from the} Final Analyses. From the general sample 170 participants were excluded from the analysis. Thus, to examine the generalizability of the sample, the differences in profile and weight characteristics between responders and nonresponders were examined.

The analysis showed no significant differences between the two groups in regards to their occupation $\left(x^{2}=2.925, \mathrm{df}\right.$ $=3, P=.403)$ and relationship status $\left(x^{2}=6.151, \mathrm{df}=5, P\right.$ $=.292)$. However, significant differences appeared between the two groups in regards to their level of education $\left(x^{2}=\right.$ 12.834, $\mathrm{df}=2, P=.002)$.
As Table 2 indicates, responders were significantly older, weighed more and had higher maximum weight than the other group. No significant differences emerged between the two groups in regards to the age of the obesity and diet onset.

\subsection{Differences Between Successful and Unsuccessful Dieters.}

(i) Differences in demographic and weight history data. The two groups were comparable in terms of occupation $\left(x^{2}=2.673\right.$, $\left.\mathrm{df}=3, P=.445\right)$, relationship status $\left(x^{2}=\right.$ 8.012 , df $=5, P=.156)$, level of education $\left(x^{2}=.861\right.$, df $=2, P=.650)$, age $(P>.05)$, and age of diet onset $(P>.05)$. Also, unsuccessful weight losers were significantly more obese than successful weight losers. In addition, for successful members their current weight was significantly less and they had higher maximum weight than unsuccessful participants. In addition, successful individuals were significantly younger when they first became overweight and lost significantly more weight which they sustained for longer than their counterparts. Table 3 shows the demographic and weight differences between the two groups. 
TABLE 2: Differences between responders and nonresponders.

\begin{tabular}{lllllcc}
\hline Variable & \multicolumn{2}{c}{ Responders $(N=980)$} & \multicolumn{2}{c}{ Non responders $(N=113)$} & $\mathrm{F}$ & Sig \\
\hline Age & $\mathrm{M}=38.6$ & $\mathrm{SD}=10.4$ & $\mathrm{M}=36.5$ & $\mathrm{SD}=11.7$ & 5.327 & $.021^{*}$ \\
BMI & $\mathrm{M}=31.7$ & $\mathrm{SD}=6.6$ & $\mathrm{M}=30.8$ & $\mathrm{SD}=8.3$ & 2.113 & .146 \\
Present weight & $\mathrm{M}=189.4$ & $\mathrm{SD}=42.1$ & $\mathrm{M}=178.1$ & $\mathrm{SD}=31.7$ & 9.648 & $.002^{*}$ \\
Highest weight excluding pregnancy & $\mathrm{M}=212$ & $\mathrm{SD}=45$ & $\mathrm{M}=197.8$ & $\mathrm{SD}=38.6$ & 13.366 & $.0001^{*}$ \\
Age first became overweight & $\mathrm{M}=19.4$ & $\mathrm{SD}=9.6$ & $\mathrm{M}=20.4$ & $\mathrm{SD}=10.06$ & 1.347 & .246 \\
Age first attempted to lose weight & $\mathrm{M}=22.8$ & $\mathrm{SD}=9.2$ & $\mathrm{M}=23.2$ & $\mathrm{SD}=8.7$ & .260 & .610 \\
\hline *P $\leq .05$ & & & & & &
\end{tabular}

TABle 3: Demographic and weight differences between the groups.

\begin{tabular}{lcc}
\hline Variable & F & Sig. \\
\hline Age & 1.131 & .288 \\
BMI & 85.29 & $.0001^{*}$ \\
Present weight & 66.91 & $.0001^{*}$ \\
Highest weight excluding pregnancy & 7.384 & $.007^{*}$ \\
Age first became overweight & 8.498 & $.004^{*}$ \\
Age first tried to lose weight & 3.691 & .055 \\
Percentage of weight loss & 1625.971 & $.0001^{*}$ \\
Months of maintenance & 88.183 & $.0001^{*}$ \\
\hline
\end{tabular}

${ }^{*} P<.05$.

(ii) Differences between successful and unsuccessful dieters for life events and sustaining conditions. Successful participants reported higher number of life events than the unsuccessful participants. Successful participants were significantly more likely to report events such as "reaching my heaviest weight", "doctor's recommendations" and "clothes did not fit me". In addition, they indicated a significantly lower agreement for the exercise, medical, and psychological causes of obesity whereas the two groups were comparable in regards to their beliefs about dietary causes. In addition, they indicated significantly more benefits from exercise, fewer benefits from eating, and more choice over healthy food and overexercise. Finally, successful participants tended to have significantly healthier habits as they ate more healthily and exercised more than the unsuccessful group (Table 4).

3.4. Differences Within the Successful Group. The data were then analyzed to explore within subject differences. The section below describes differences within the successful participants group as they described their weight experiences during their heaviest weight (Time 1) and while maintaining their weight loss (Time 2). The analysis concentrates in the individuals' behavioural solutions, choice, and functionality over their previous unhealthy and current healthy behaviour (see Table 5).

The analyses showed significant differences within the successful dieters group concerning their experiences before and after weight loss. Before weight loss, successful members experienced more benefits from eating, fewer benefits from exercise and more choice over unhealthy food and less choice over exercise. On the contrary, during sustained weight loss they experienced more benefits from their new healthy behaviours and less choice over their previous unhealthy behaviours.

\section{Discussion}

Research to date indicates that only a small minority of those who try to lose weight are successful in the longer term. The present study aimed to explore the role of life events and a number of sustaining conditions in explaining sustained changes in diet and exercise and subsequent weight loss maintenance.

The results indicated that the successful and unsuccessful dieters were comparable in terms of all measured demographic factors. Consistent differences were however found in terms of life events and the sustaining conditions.

In particular, successful individuals reported more sudden life events, prior to weight loss, than unsuccessful individuals. In particular, they were more likely to indicate that events such as "reaching my heaviest weight", "doctor's recommendations", and "clothes did not fit" than unsuccessful participants. This supports previous research which indicates that life events can trigger behaviour change $[8$, 13], whereby people respond to such events by changing towards a healthier set of behaviours. Research in nutrition behaviour also argued that life events or turning points in people's trajectories mark drastic changes especially when they occur at a particular vulnerable period for the individual. This change causes them to think differently about their unhealthy behaviour and about themselves as unhealthy eaters $[15,16]$. Therefore, although much research explores behaviour change as the end result of a gradual shift in decision making $[2,17]$, the results from the present study indicate that at times behaviour change may occur in a more sudden, less planned way after a life event $[6,11$, $18]$.

The results also showed consistent differences between the two groups in terms of the sustaining conditions measured. In particular, those who had been successful in their weight loss maintenance were more likely to endorse behavioural attributions and solutions to their weight problem, to report lower benefits to eating and greater benefits from exercise and to describe their choice over eating as reduced while their choice over exercise was increased. These results provide support for the sustaining conditions outlined in previous qualitative research [13]. Further, they support the role of coherence between beliefs about causes and solutions [19] and indicate that a reduction of choice over the old unhealthy behaviour can promote behaviour change [20].

Therefore, the results from the between subjects analysis, provide quantitative support for previous research which 
TABLE 4: Differences between successful and unsuccessful participants related to life events and sustaining conditions.

\begin{tabular}{|c|c|c|c|c|c|c|}
\hline \multirow{2}{*}{$\begin{array}{l}\text { Variable } \\
\text { Life Events }\end{array}$} & \multicolumn{2}{|c|}{ Successful $(N=222)$} & \multicolumn{2}{|c|}{ Unsuccessful $(N=316)$} & \multirow{2}{*}{$\begin{array}{c}\mathrm{F} \\
519.179\end{array}$} & \multirow{2}{*}{$\begin{array}{c}\text { Sig. } \\
.0001^{*}\end{array}$} \\
\hline & $\mathrm{M}=4.45$ & $\mathrm{SD}=1.644$ & $\mathrm{M}=1.46$ & $\mathrm{SD}=1.39$ & & \\
\hline \multicolumn{7}{|c|}{ Beliefs about causes: } \\
\hline Exercise & $\mathrm{M}=11.88$ & $\mathrm{SD}=2.825$ & $\mathrm{M}=13.05$ & $\mathrm{SD}=2.452$ & 26.081 & $.0001^{*}$ \\
\hline Diet & $\mathrm{M}=13.00$ & $\mathrm{SD}=2.715$ & $\mathrm{M}=13.09$ & $\mathrm{SD}=2.412$ & .144 & .705 \\
\hline Medical & $\mathrm{M}=8.39$ & $\mathrm{SD}=2.977$ & $\mathrm{M}=10.73$ & $\mathrm{SD}=2.693$ & 90.509 & $.0001^{*}$ \\
\hline Psychological & $\mathrm{M}=11.13$ & $\mathrm{SD}=2.603$ & $\mathrm{M}=11.79$ & $\mathrm{SD}=2.721$ & 7.861 & $.005^{*}$ \\
\hline \multicolumn{7}{|c|}{ Reduction of choice: } \\
\hline Diet & $M=16.19$ & $\mathrm{SD}=3.730$ & $\mathrm{M}=17.8$ & $\mathrm{SD}=4.091$ & 21.744 & $.0001^{*}$ \\
\hline Exercise & $\mathrm{M}=6.14$ & $\mathrm{SD}=1.718$ & $\mathrm{M}=7.4$ & $\mathrm{SD}=2.020$ & 59.940 & $.0001^{*}$ \\
\hline \multicolumn{7}{|l|}{ Functionality: } \\
\hline Diet & $\mathrm{M}=7.37$ & $\mathrm{SD}=3.261$ & $\mathrm{M}=8.98$ & $\mathrm{SD}=4.248$ & 22.556 & $.0001^{*}$ \\
\hline Exercise & $\mathrm{M}=8.17$ & $\mathrm{SD}=2.947$ & $M=6.9$ & $\mathrm{SD}=2.747$ & 25.770 & $.0001^{*}$ \\
\hline \multicolumn{7}{|l|}{ Behaviours: } \\
\hline Diet & $M=29.50$ & $\mathrm{SD}=3.123$ & $M=27.61$ & $\mathrm{SD}=3.619$ & 39.908 & $.0001^{*}$ \\
\hline Exercise & $\mathrm{M}=11.48$ & $\mathrm{SD}=1.658$ & $M=10.45$ & $\mathrm{SD}=1.881$ & 42.912 & $.0001^{*}$ \\
\hline
\end{tabular}

TABle 5: Differences within the successful weight losers between Time 1 and Time $2(N=222)$.

\begin{tabular}{|c|c|c|c|c|c|}
\hline Variable & \multicolumn{2}{|c|}{ Heaviest (Time 1) } & \multicolumn{2}{|c|}{ Past month (Time 2) } & Sig. \\
\hline \multicolumn{6}{|c|}{ Functionality: } \\
\hline Diet & $M=13.83$ & $\mathrm{SD}=4.231$ & $\mathrm{M}=7.35$ & $\mathrm{SD}=3.238$ & $.0001^{*}$ \\
\hline Exercise & $\mathrm{M}=7.68$ & $\mathrm{SD}=3.094$ & $M=8.18$ & $\mathrm{SD}=2.960$ & $.0001^{*}$ \\
\hline \multicolumn{6}{|l|}{ Behaviours: } \\
\hline Diet & $M=20.18$ & $\mathrm{SD}=4.489$ & $M=29.58$ & $\mathrm{SD}=3.101$ & $.0001^{*}$ \\
\hline Exercise & $\mathrm{M}=8.35$ & $\mathrm{SD}=1.919$ & $\mathrm{M}=11.49$ & $\mathrm{SD}=1.729$ & $.0001^{*}$ \\
\hline \multicolumn{6}{|l|}{ Choice: } \\
\hline Diet & $M=22.46$ & $\mathrm{SD}=3.986$ & $M=16.23$ & $\mathrm{SD}=3.710$ & $.0001^{*}$ \\
\hline Exercise & $\mathrm{M}=9.61$ & $\mathrm{SD}=1.206$ & $M=6.16$ & $\mathrm{SD}=1.749$ & $.0001^{*}$ \\
\hline
\end{tabular}

$* P \leq .05$.

highlights the role of triggers and a number of sustaining conditions in promoting longer term changes in behaviour. The role of these factors was further evidenced in the within subjects analysis. In particular, compared to a time prior to their weight loss, the successful dieters reported greater benefits from exercise and less from eating and increased choice over exercise and reduced choice over eating. Accordingly, the results from both between and within subjects' analysis indicate that triggers can promote behaviour change and that this is further facilitated by the choice and function of the behaviours being considered.

There are however, some problems with this study that need to be considered. Firstly, the participants were mainly white women who attended a slimming club with the aim to lose weight which limits the generalisability to other populations. The results may also not be representative of those who have been successful but are no longer involved with the dieting industry. Secondly, the study relied upon self-reported weights and weight change which may be influenced by problems of social desirability and recall bias [21]. There might be some potential differences in recall bias between the groups since for unsuccessful weight losers the time interval between the event and the time of assessment (past month) was shorter than that of the successful participants who were asked to report their weight management experiences when they were at their heaviest. Therefore, the time between the assessment and the event was longer for the latter group and thus the probabilities for a false recall might be higher [22]. Thirdly, some of the data was retrospective and asked participants to describe their beliefs about aspects of their behaviour in the past compared to the present. Again, this approach is likely to be influenced by issues of self comparison and recall bias. This provides a basis for future prospective examination of these factors to explore whether recall bias and reporting beliefs of the past influence the validity and reliability of participants' reports. Finally, the length of time participants had a membership was not included in the study and this might had influenced their reports in weight loss, sustained weight loss, choice of food, and physical activity. 
The results from the present study do, however, provide some insights into the factors associated with weight loss maintenance and sustained changes in diet and exercise. In particular using both a within and a between subjects design, the results indicate that behaviour change can be triggered by specific life events. In addition to this, the current study also highlights that this healthy behaviour change is translated into a sustained behaviour change if a number of sustaining conditions are met. In particular, the results highlight the role of choice and the function of the behaviour and provide quantitative data to support previous qualitative research.

\section{References}

[1] M\&NP. Conner, Predicting Health Behavior, Open University Press, Oxford, UK, 2005.

[2] K. Resnicow and R. Vaughan, "A chaotic view of behavior change: a quantum leap for health promotion," International Journal of Behavioral Nutrition and Physical Activity, vol. 3, article 25, 2006.

[3] A. J. Rothman, "Toward a theory-based analysis of behavioral maintenance," Health Psychology, vol. 19, no. 1, supplement, pp. 64-69, 2000.

[4] A. A. Gorin, S. Phelan, J. O. Hill, and R. R. Wing, "Medical triggers are associated with better short- and long-term weight loss outcomes," Preventive Medicine, vol. 39, no. 3, pp. 612616, 2004.

[5] L. C. Larabie, "To what extent do smokers plan quit attempts?" Tobacco Control, vol. 14, no. 6, pp. 425-428, 2005.

[6] H. Matzger, L. A. Kaskutas, and C. Weisner, "Reasons for drinking less and their relationship to sustained remission from problem drinking," Addiction, vol. 100, no. 11, pp. 16371646, 2005.

[7] W. R. Miller, "The phenomenon of quantum change," Journal of Clinical Psychology, vol. 60, no. 5, pp. 453-460, 2004.

[8] J. Ogden and S. Sidhu, "Adherence, behavior change, and visualization: a qualitative study of the experiences of taking an obesity medication," Journal of Psychosomatic Research, vol. 61, no. 4, pp. 545-552, 2006.

[9] R. R. Wing and S. Phelan, "Long-term weight loss maintenance," The American Journal of Clinical Nutrition, vol. 82, no. 1, supplement, pp. 222S-225S, 2005.

[10] J. E. Tinker and J. A. Tucker, "Environmental events surrounding natural recovery from obesity," Addictive Behaviors, vol. 22, no. 4, pp. 571-575, 1997.

[11] R. West and T. Sohal, "“Catastrophic" pathways to smoking cessation: findings from national survey," British Medical Journal, vol. 332, no. 7539, pp. 458-460, 2006.

[12] P. J. Brink and K. Ferguson, "The decision to lose weight," Western Journal of Nursing Research, vol. 20, no. 1, pp. 84-102, 1998.

[13] J. Ogden and L. Hills, "Understanding sustained behavior change: the role of life crises and the process of reinvention," Health, vol. 12, no. 4, pp. 419-437, 2008.

[14] R. R. Wing and J. O. Hill, "Successful weight loss maintenance," Annual Review of Nutrition, vol. 21, pp. 323-341, 2001.

[15] E. Wethington, "An overview of the life course perspective: implications for health and nutrition," Journal of Nutrition Education and Behavior, vol. 37, no. 3, pp. 115-120, 2005.
[16] C. M. Devine, "A life course perspective: understanding food choices in time, social location, and history," Journal of Nutrition Education and Behavior, vol. 37, no. 3, pp. 121-128, 2005.

[17] M. H. Kearney and J. O'Sullivan, "Identity shifts as turning points in health behavior change," Western Journal of Nursing Research, vol. 25, no. 2, pp. 134-152, 2003.

[18] J. M. Brown, "Redefining smoking and the self as a nonsmoker," Western Journal of Nursing Research, vol. 18, no. 4, pp. 414-428, 1996.

[19] J. Ogden and A. Jubb, "How consistent are beliefs about the causes and solutions to illness? An experimental study," Psychology, Health and Medicine, vol. 13, no. 5, pp. 505-515, 2008.

[20] J. Ogden, C. Clementi, S. Aylwin, and A. Patel, "Exploring the impact of obesity surgery on patients' health status: a quantitative and qualitative study," Obesity Surgery, vol. 15, no. 2, pp. 266-272, 2005.

[21] AJ\&MGJ. Silman, Epidemiological Studies, Cambridge University Press, Cambridge, UK, 2002.

[22] B. M. Margetts, H. H. Vorster, and C. S. Venter, "Evidencebased nutrition - the impact of information and selection bias on the interpretation of individual studies," South African Journal of Clinical Nutrition, vol. 16, no. 3, pp. 79-87, 2003. 


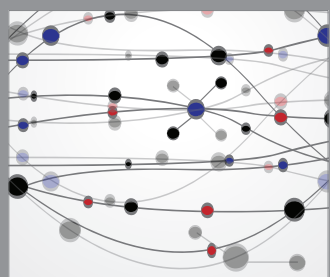

The Scientific World Journal
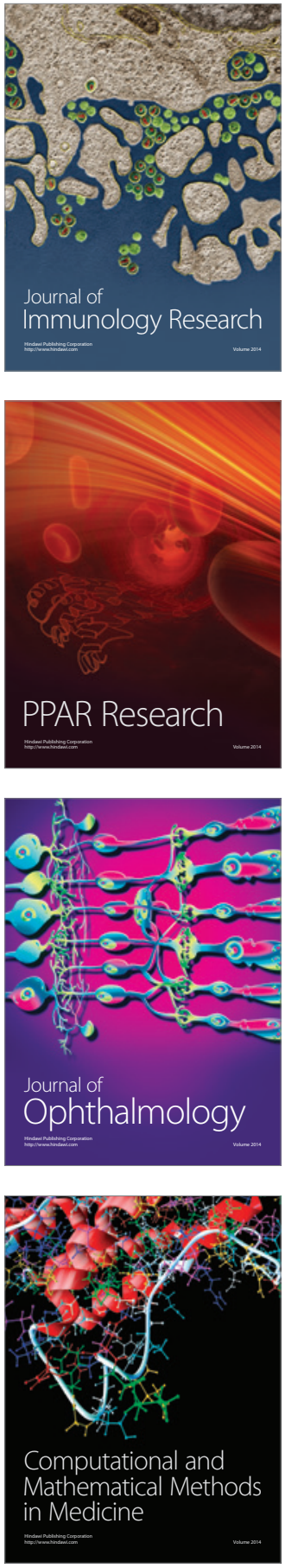

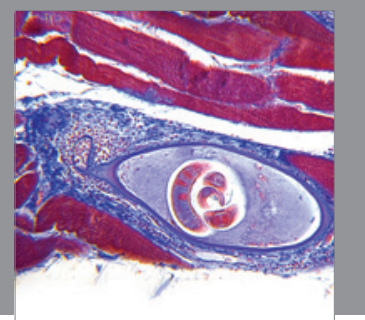

Gastroenterology

Research and Practice
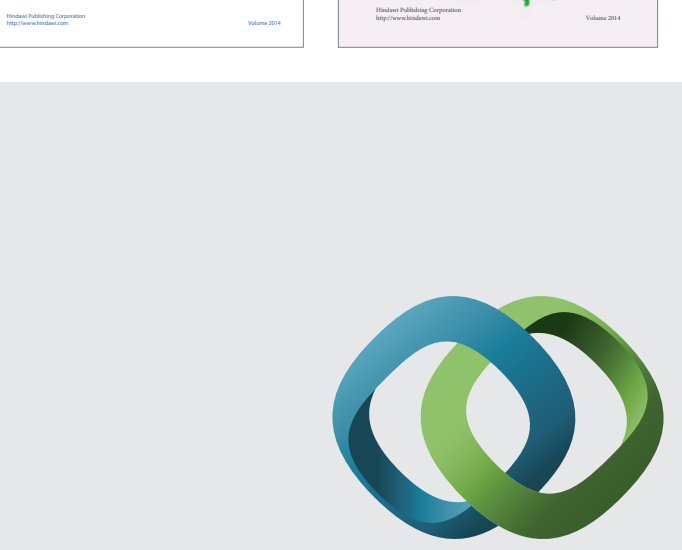

\section{Hindawi}

Submit your manuscripts at

http://www.hindawi.com
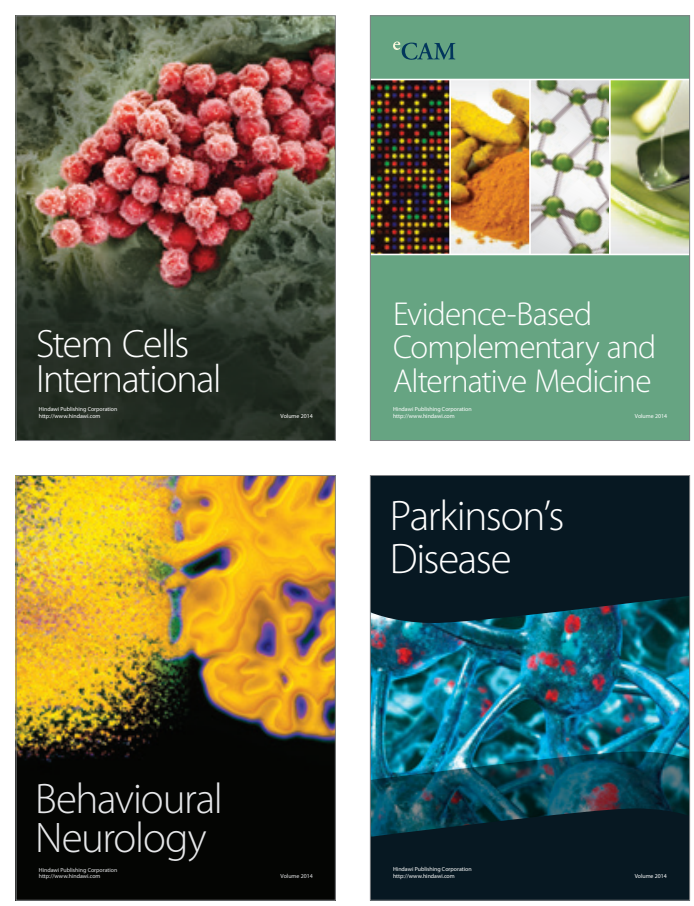

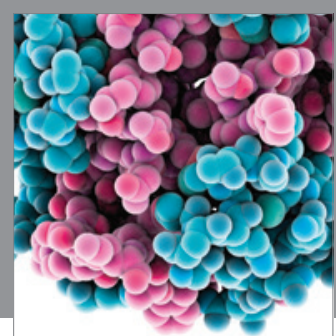

Journal of
Diabetes Research

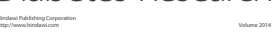

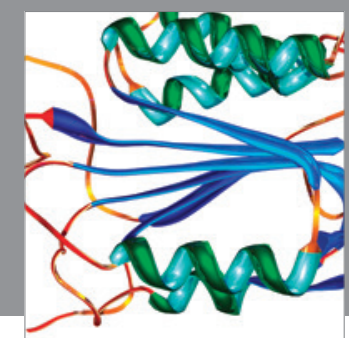

Disease Markers
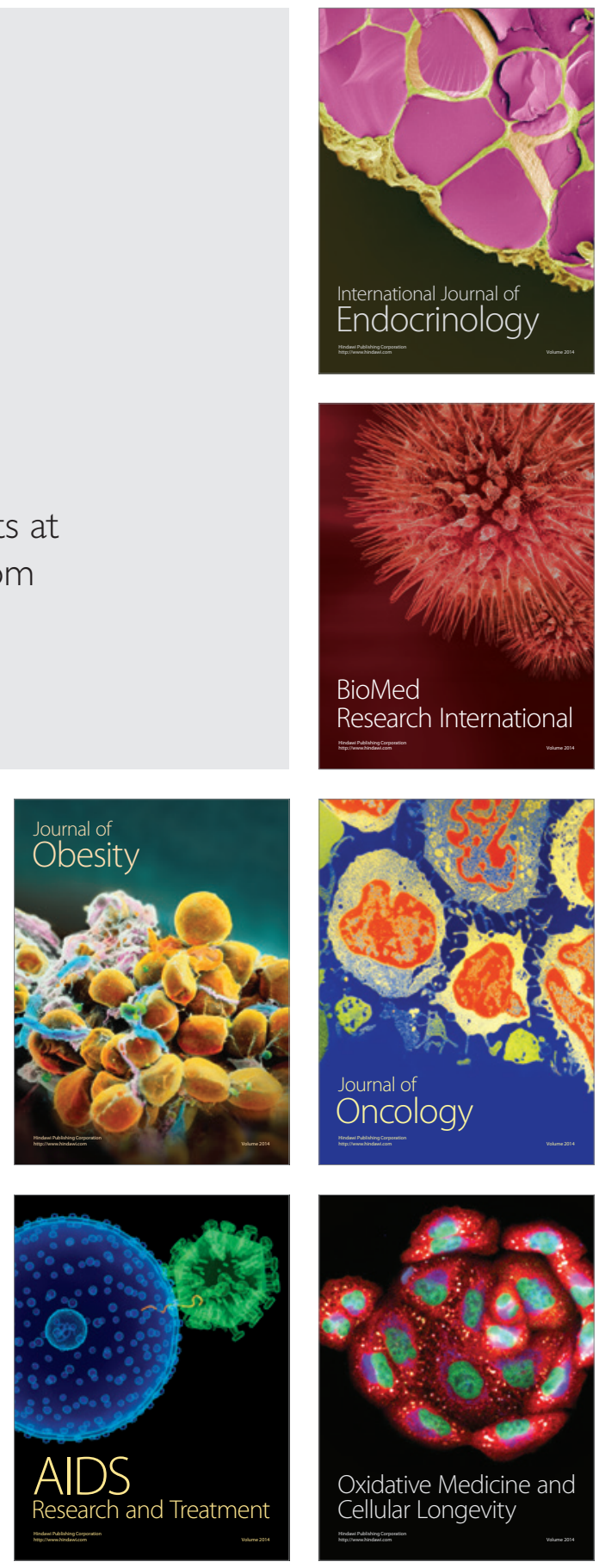